\title{
NƯMERO DE LOCOS E AÇÃO GÊNICA DE FATORES PARA PORTE PEQUENO EM COFFEA ARABICA L. ${ }^{(1)}$
}

\author{
ALCIDES CARVALHO, herCULANo PENNA MEDINA FilHo, LUIZ CARLOS FAZUOLI e
} WALDIR MARQUES DA COSTA. Seção de Genética, Instituto Agronómico de Campinas (2).

\section{RESUMO}

Analisaram-se, geneticamente, os fatores que reduzem a altura das plantas nos seguintes cultivares de Coffea arabica: Caturra (C 476, C 477), San Bernardo (C 1039), Pacas (C 1467), Vila Sarchi (C 1468), San Ramón x Bourbon (C 1036), Vila Lobos (C 1089) e San Ramón (C 457 e C 601). Realizaram-se cruzamentos com o cultivar Arábica, tomado como padrão e entre eles. As conclusões relatadas são resultantes do estudo de 91.358 plantas, envolvendo gerações $S_{1}, S_{2}, S_{3}, F_{1}$ e $F_{9}$, retrocruzamentos e cruzamentos-teste. O porte reduzido em cada cultivar é devido a um fator simples, dominante em relação ao alelo do Arábica. Três locos foram identificados - São Bernardo (Sb), San Ramón (Sr) e Caturra (Ct) - segregando independentemente, em combinações diíbridas. Possivelmente, outros locos estejam também envolvidos. Pacas e Vila Sarchi possuem alelos para o mesmo loco, enquanto o fator da introdução C 1036 é alelo a Ct. Não há informações precisas se o fator de Vila Lobos é alelo a Sr, embora ambos segreguem independentemente dos fatores Ct e Sb, e o fator presente em Vila Lobos seja independente também daquele presente em Pacas e Vila Sarchi. As análises em progênies das gerações $F_{1}$ e $F_{2}$ e de retrocruzamentos de plantas com dois quaisquer desses fatores revelaram uma interação interlocos do tipo epistasia duplo dominante. A presença

(1) Trabalho apresentado no $\mathrm{X}$ Colóquio da Associatión Scientifique internacionale du Café, Salvador, Brasil, 11-14 outubro, 1982. Recebido para publicaçăo a 28 de março de 1983.

(2) Trabalho executado com auxilio do Conselho Nacional de Desenvolvimento Cientifico e Tecnológico e do Instituto Brasileiro do Café. 


\begin{abstract}
de um alelo dominante em um loco mascara o efeito de cutro fator dominante. Plantas homozigotas ou heterozigotas para um alelo dominante em um ou dois locos são visualmente indistinguiveis pela altura. Mediante hibridações com o cafeeiro Murta, verificou-se serem o San Ramón derivado do Arábica e o Caturra, do Bourbon.
\end{abstract}

\title{
1. INTRODUÇÃO
}

A redução na altura das plantas tem sido um dos objetivos comuns a muitos programas de melhoramento em plantas econômicas. Em alguns cereais, a importância reside no fato de as plantas com porte reduzido poderem receber niveis mais elevados de fertilizantes, sem se acamarem $(\boldsymbol{2}, \mathbf{2 0}, \mathbf{2 3})$. O impacto econômico desses novos cultivares é amplamente reconhecido (22). Em plantas perenes, como as frutíferas, o porte reduzido permite o plantio em espaçamentos mais densos, além de facilitar as operações de colheita e tratamentos fitossanitários (12).

No cafeeiro, o plantio de cultivares de porte reduzido e com alta produtividade é um consenso amplamente difundido e de reconhecidas vantagens econômicas, a julgar pela extensão dos novos plantios no Brasil com o cultivar Catuaí de Coffea arabica (8). Cabe, ainda, salientar que o aumento da lucratividade com o emprego de cultivares de porte reduzido dá-se não somente pela maior densidade de plantio como, também, pela redução dos custos de colheita, os quais representam $20-40 \%$ do custo de produção do café. Em outros países cafeicultores, a preferência para cultivares de porte reduzido também se verifica, principalmente naqueles cujas culturas são estabelecidas em espaçamentos bastante reduzidos $(\mathbf{1 3}, \mathbf{2 7})$.

Diversos são os cultivares de Coffea arabica que possuem porte baixo. O mais conhecido entre nós é o cultivar Catuaí, cujo porte reduzido é proveniente do Caturra. Outros cultivares, como São Bernardo, San Ramón, Pacas, Vila Sarchi e Vila Lobos, também possuem essa característica desejável. Mutações que reduzem o comprimento dos internódios ocorrem em C. canephora (15), espécie que é, também, economicamente cultivada.

Uma vez que a estratégia e o potencial do melhoramento dependem da natureza genética que condiciona o porte reduzido $\epsilon$ da açāo gênica envolvida, existe grande interesse na análise genética dessa característica. Cultivares com porte reduzido têm sido observados em várias espécies econômicas. PELTON (21) relata a ocorrência de 112 genes simples controlando essa característica em 34 gêneros de 16 famílias de plantas superiores. Na maioria dos casos em que a genética foi devidamente estudada, diversos fatores independentes, recessivos, interagindo de forma aditiva, foram identificados. 
Neste trabalho são relatados os resultados de um extenso programa de análise genética visando a maior conhecimento dos fatores presentes nos cultivares de $\mathbf{C}$. arabica mencionados.

\section{MATERIAL E METTODOS}

\subsection{Cultivares e introduções estudadas}

Não há muitas informações sobre a origem dos cultivares de porte pequeno utilizados nas análises genéticas.

O cafeeiro Caturra aparentemente é uma mutação natural, identificada entre 1915 e 1917 em Lessa, no município de Manhumirim (MG), onde era conhecido por Café Caturra ou Nanico. Em Campinas, as primeiras amostras de sementes foram recebidas em 1937 de Caturra Amarelo (C 476) e Caturra Vermelho (C 477), oriundas de plantaçōes do município de Siqueira Campos (ES). É interessante riotar a existência, nessas plantaçōes, das formas de frutos vermelhos e amarelos. Não se sabe se a mutação Caturra ocorreu em Lessa ou se algum lavrador a trouxe de outra localidade. O Caturra se caracteriza por apresentar porte pequeno, internódios curtos, forma mais cilíndrica do arbusto, ramos laterais e de ordem inferior abundantes, folhas de um verde intenso pouco maiores do que as do Bourbon Vermelho (C. arabica cv. Bourbon Vermelho). Flores, frutos e sementes são semelhantes aos deste cultivar e, a produção, pouco menor. Devido à alta capacidade produtiva e falta de vigor, pode apresentar morte dos ramos em um ano de elevada colheita com sensível redução na subseqüente produção (16).

Segundo GONZALEZ (10), o cafeeiro Pacas é derivado do Bourbon Vermelho e corresponde ao Caturra e ao Vila Sarchi, de Costa Rica. É de porte menor que o do Bourbon, de entrenós curtos e ramificações secundárias intensas e folhas maiores, e de cor verde-escura. $O$ aspecto do arbusto é compacto, com qualidades que favorecem o seu cultivo, pois apresenta resistência aos ventos e à seca, motivo pelo qual o seu plantio é recomendado a regiōes de muito vento e baixa altitude de El Salvador. A produção é considerada boa, e supõe-se ter maior resistência a Cercospora sp. do que o cultivar Bourbon Vermelho, sendo adaptado aos tipos de poda usados nesse país. Em Campinas, amostra de stementes do cafeeiro Pacas (C 1467) foi recebida em 1966 diretamente do Instituto Interamericano de Ciências Agrícolas, Turrialba, Costa Rica. As plantas obtidas assemelham-se às do Caturra.

O cafeeiro Vila Sarchi é originário de Costa Rica e também apresenta porte e aparência de Caturra (11). Em 1966 foram recebidas em Campinas sementes do Vila Sarchi (C 1468) procedentes de Costa Rica. As plantas obtidas se parecem com as do Caturra.

O cafeeiro San Ramón, de acordo com CHOUSSI (9), é originário do cantão San Ramón, Costa Rica, onde é também conhecido por caf́é 
Enano ou San Lorenzo. Era encontrado nos jardins de quase todas as residências da região e supōe-se ser derivado do cultivar Arábica de C. arabica. A designação San Lorenzo está relacionada com o rio desse mesmo nome, que nasce no cantão San Ramón. Os entrenós são muito curtos, as folhas elíticas, verde-escuras, base e ápice obtusos; é precoce no florescimento e tardio no amadurecimento dos frutos. Desenvolve bem em lugares expostos aos ventos, porém a produção é pequena (9). Duas introduções do cafeeiro San Ramon existem em Campinas: a primeira (C 457) originária de Santa Tecla, El Salvador, e recebida em 1937 e, a segunda (C 601), oriunda de Chinchina, Colômbia, e obtida em 1940. Os exemplares estudados têm porte menor do que o do Caturra.

Também de Turrialba, Costa Rica, foram recebidas, em 1953, sementes do cafeeiro Vila Lobos (C 1089), que é originário desse país. Tem porte maior que o San Ramon, porém os internódios são bastante curtos. A produção é pouco maior do que a do Arábica e tem boa adaptação a regiōes de maior altitude (2). As plantas analisadas em Campinas têm semelhança às do San Ramón, embora atinjam maior altura.

Sementes de um cefeeiro tido como híbrido de San Ramón com Bourbon (C 1036) foram recebidas em 1950 de El Salvador, e sua descendência foi analisada por apresentar, também, porte reduzido. Não há referência específica sobre essa introdução. As plantas obtidas assemelham-se às do Caturra.

O cafeeiro São Bernardo, conhecido por café Pache (pequeno), é oriundo da Guatemala, El Trapichito, Santa Cruz Naranjo, Departamento Santa Rosa, de onde foram remetidas sementes para Campinas (C 1039), em 1950. Parece ser derivado do cultivar Arábica de Coffea arabica e tem internódios curtos, o que reduz bastante a altura da planta, tornando-a menor do que a do Caturra.

Os careeiros Arábica e Bourbon foram considerados como padrões nas análises genéticas realizadas em Campinas (1). O primeiro corresponde ao Arábica de C. arabica, descrito por Cramer, e serviu de base para a descrição da espécie por Lineu. Originário da Etiópia, é cultivado em vários países americanos e, por muitos anos, foi um dos únicos cultivares plantados no Brasil. O Bourbon originou-se na ilha Bourbon, na África. Em 1859 foi introduzido no Brasil, onde foi extensivamente cultivado no Estado de São Paulo (17).

\subsection{Autofecundações e hibridações realizadas}

Cruzamentos e autofecundaçōes controladas foram realizadas de acordo com as técnicas descritas por KRUG (14) e utilizadas rotineiramente na Seção de Genética. Progênies $S_{1}$ e $S_{2}$ referem-se, respectivamente, aos descendentes da primeira e da segunda geração de auto- 
polinização ou de polinização livre. Como C. arabica é uma espécie predominantemente autógama $(4,6)$, cerca de $4-10 \%$ apenas de fecundação cruzada, algumas progênies $S_{1} \oplus \mathbf{S}_{2}$, obtidas de flores de polinização aberta, foram também consideradas, para o caso em estudo, como resultantes de autofecundações. Nas hibridações de cafeeiros de porte reduzido, usaram-se os cultivares Arábica e Bourbon Vermelho, tomados como padrão de porte normal nas análises genéticas (1).

\subsection{Métodos de análise}

A classificação das plantas foi feita em condiçōes de viveiro, quando as plantas tinham 12 a 15 meses de idade. Visualmente, as plantas de cada progênie foram agrupadas em duas classes: porte normal (PN) ou reduzido (PR) de acordo com a altura e com o cultivar em estudo. Nos casos em que as populações segregantes eram derivadas do cruzamento de dois cultivares de porte reduzido, tentou-se subclassificar o grupo de plantas de porte reduzido, de acordo com o fenótipo geral dos tipos parentais. Algumas combinações foram analisadas no campo, principalmente aquelas envolvendo cruzamentos de San Ramón e São Bernardo com o Mundo Novo (5), e de São Bernardo com Caturra, devido ao interesse do aproveitamento dessas combinações no programa de melhoramento.

A proporção fenotípica de plantas em cada classe foi analisada pelo teste de quiquadrado $\left(\chi^{2}\right)$. $\mathrm{Na}$ análise dos dados de segregação em que apenas duas classes eram reconhecidas (porte reduzido e porte normal), utilizou-se a correção de Yates para continuidade, uma vez que, com duas classes, tem-se apenas um grau de liberdade $(\mathbf{1 8}, \mathbf{2 6})$.

De acordo com os principios mendelianos, na geração $F_{2}$, um par de fatores segrega na proporção genotípica de 1:2:1. Tratando-se de fatores dominantes, as duas primeiras classes (homozigotas e heterozigotas) são indistinguíveis. Observa-se então a razão fenotípica de $3: 1$ ou de 15:1, no caso da segregação para dois pares de fatores. Da mesma forma, cruzamentos-teste (cruzamento entre plantas heterozigotas e plantas homozigotas para alelo(s) recessivo(s), resultam em progênies segregando na razão $1: 1$ ou $3: 1$, dependendo de um ou dois pares de fatores estarem segregando. Evidentemente, a razão fenotípica observada nas gerações $F_{2}$ e nos cruzamentos-teste indica se os fatores presentes nos cultivares que participaram dos cruzamentos são alelos do mesmo loco ou de locos diferentes. Em outras palavras, esses são os cruzamentos criticos para o teste de alelismo, quando ocorrem interações interalélicas do tipo epistasia duplo dominante, como será discutido adiante.

Nos casos em que o $F_{1}$ entre dois cultivares possuindo alelos do mesmo loco para porte reduzido foi cruzado com plantas de porte normal, o termo cruzamento-teste não é totalmente apropriado, uma vez que se trata de um cruzamento entre homozigotos. Com essa ressalva, a termi- 
nologia, porém, foi mantida, indistintamente, referindo-se a cruzamentos entre $F_{I}$ e plantas de porte normal.

\section{RESULTADOS E DISCUSSÃO}

Devido à grande quantidade de progênies individualmente analisadas, são apresentados nos quadros 1,2 e 3 apenas os resumos dessas análises. Para cada caso, é indicado o total de plantas nas categorias porte reduzido (PR) e porte normal ( $\mathrm{PN}$ ), o número de progênies individualmente analisadas e, entre estas, o número de progênies cujos dados de segregação não diferem significativamente da proporção teóricł testada, fixado o nivel de $5 \%$.

No quadro 1 , pode ser observado, pelos resultados das progênies $S_{1}$, $S_{2}$ e $S_{3}$ dos cultivares introduzidos, que nem todos os materiais eram uniformes. Alguns eram originalmente homozigotos, enquanto outros segregaram para a característica porte reduzido. Assim, Facas (C 1467), Caturra (C 476, C 477) e São Bernardo (C 1039) revelaram-se introduções homogêneas, nas quais somente plantas de porte reduzido foram observadas, bem como nos seus descendentes (a planta normal observada no Pacas deve possivelmente ser erro de classificação). Por outro lado, o oposto se verificou para as demais introduções, onde foram notadas plantas de porte reduzido e porte normal em algumas progênies. Entre as primeiras, muitas revelaram ser heterozigotas, conforme demonstrado pela segregação nas respectivas progênies. Por exemplo, entre as 17 plantas analisadas da introdução C 1089 de Vila Lobos, 15 se mostraram homozigotas (total $621 \mathrm{PR}$ e $1 \mathrm{PN}$ ), enquanto duas progênies eram heterozigotas, segregando, individualmente, na proporção 3 PR:1 PN. Observa-se, também, uma heterogeneidade quanto ao genótipo de algumas introduções, particularmente do cultivar San Ramón (C 457 e C 601), onde, entre as 20 progênies heterozigotas analisadas, 13 segregaram na proporção $3 \mathrm{PR}: 1 \mathrm{PN}$, enquanto seis apresentaram segregação de 15 PR:1 PN, sugerindo a presença de dois fatores dominantes condicionando a característica porte reduzido nessas progênies. Embora essa possibilidade seja viável, devido à evidente heterogeneidade observada no material original, podem ter ocorrido cruzamentos naturais entre esse cultivar e outros de porte reduzido no local de onde foram introduzidos ou que, em algumas plantas, realmente ocorrem genes duplicados. A presença de alelos dominantes em dois locos diferentes no San Ramón (C 457) pode ser também verificada nas segregaçōes de seis progênies $F_{1}$ resultantes de cruzamento com plantas normais (Quadro 2). Somente aquelas plantas segregando para um par de fatores foram utilizadas em cruzamentos com outros cultivares para a realização da análise genética.

A falta de informações precisas sobre o material introduzido é evidenciada na análise da introdução C 1036 (Quadro 1), recebida como um híbrido San Ramón $x$ Bourbon: os resultados revelaram que o fator 
presente nesse suposto híbrido é alelo daquele que ocorre no Caturra, embora o San Ramón possua um fator que segrega independentemente do fator Ct, como será discutido adiante. Como a introdução C 1036 veio de El Salvador em 1950, fica evidenciada a ocorrência do fator Caturra, na região, já nessa época. Com relação a Vila Sarchi, somente uma progênie se mostrou homozigota, enquanto, das quatro remanescentes, uma apresentou segregação monogênica, uma apareniemente segrega para dois pares de fatores, enquanto as demais, apesar de segregarem, as proporçōes não foram típicas a nenhuma razão fenotípica lógica, provavelmentè devido a dificuldades na classificação em viveiro.

Os dados do quadro 1 sugerem ainda que a caracteristica porte reduzido é condicionada por genes dominantes em relação ao porte normal.

Os resultados das gerações $F_{1}, F_{2}$, retrocruzamentos e cruzamentos-teste apresentados no quadro 2 confirmam, amplamente, essa hipótese de dominância. Do cruzamento $\mathrm{PR} \times \mathrm{PN}$, bem somo retrocruzamentos para o progenitor de PR, resultam plantas com fenótipo porte reduzido. Cruzamentos-teste ( $(P R \times P N)$ x PN) segregam na razão fenotípica 1 PR:1 PN e, a geração $\mathrm{F}_{2}$, na proporção 3 PR:1 PN. Cabe salientar, novamente, que o aparecimento ocasional de algumas poucas plantas de genótipo PN do cruzamento PR x PN como San Ramón 601 x Normal ou Vila Lobos $\mathrm{x}$ Normal, provavelmente se deva a enganos na classificação ou à mistura de algumas sementes, o que, no entanto, não invalida as conclusōes. Da mesma forma, o fato de a segregação em algumas progênies de determinado cruzamento se desviar significativamente das proporções esperadas, enquanto as demais do mesmo cruzamento apresentam uma segregação normal, seria esperado pela teoria de probabilidade, como simples acaso ou pelo fato de algumas populaçōes não serem suficientemente numerosas.

No quadro 3 são apresentados os resultados das análises de progênies derivadas de cruzamentos entre os diversos materiais estudados.

Pela teoria genética, $0 \mathrm{~F}_{2}$ e 0 cruzamento-teste do $\mathrm{F}_{1}$ entre plantas possuindo alelos para um mesmo loco são uniformes, rão segregando para a caracteristica em estudo. Nos cruzamentos entre plantas possuindo alelos para dois locos diferentes, observam-se, no $F_{2}$ e cruzamento-teste, segregações diíbridas, sendo o número de classes fenotípicas e suas proporções dependentes da ação gênica e do tipo de interação interlocos. No presente caso, verifica-se, claramente, que qualquer um dos dois locos em combinação estudados interagem de forma denominada epistasia tipo duplo dominante, na qual a presença de um alelo dominante condicionando porte reduzido em um loco mascara o efeito de outro loco. Dessa forma, no $F_{2}$ observam-se apenas duas classes porte reduzido e porte normal - na proporção 15:1 respectivamente. No caso de cruzamento-teste, essas duas classes ocorrem, portanto, na freqüência 3:1. 


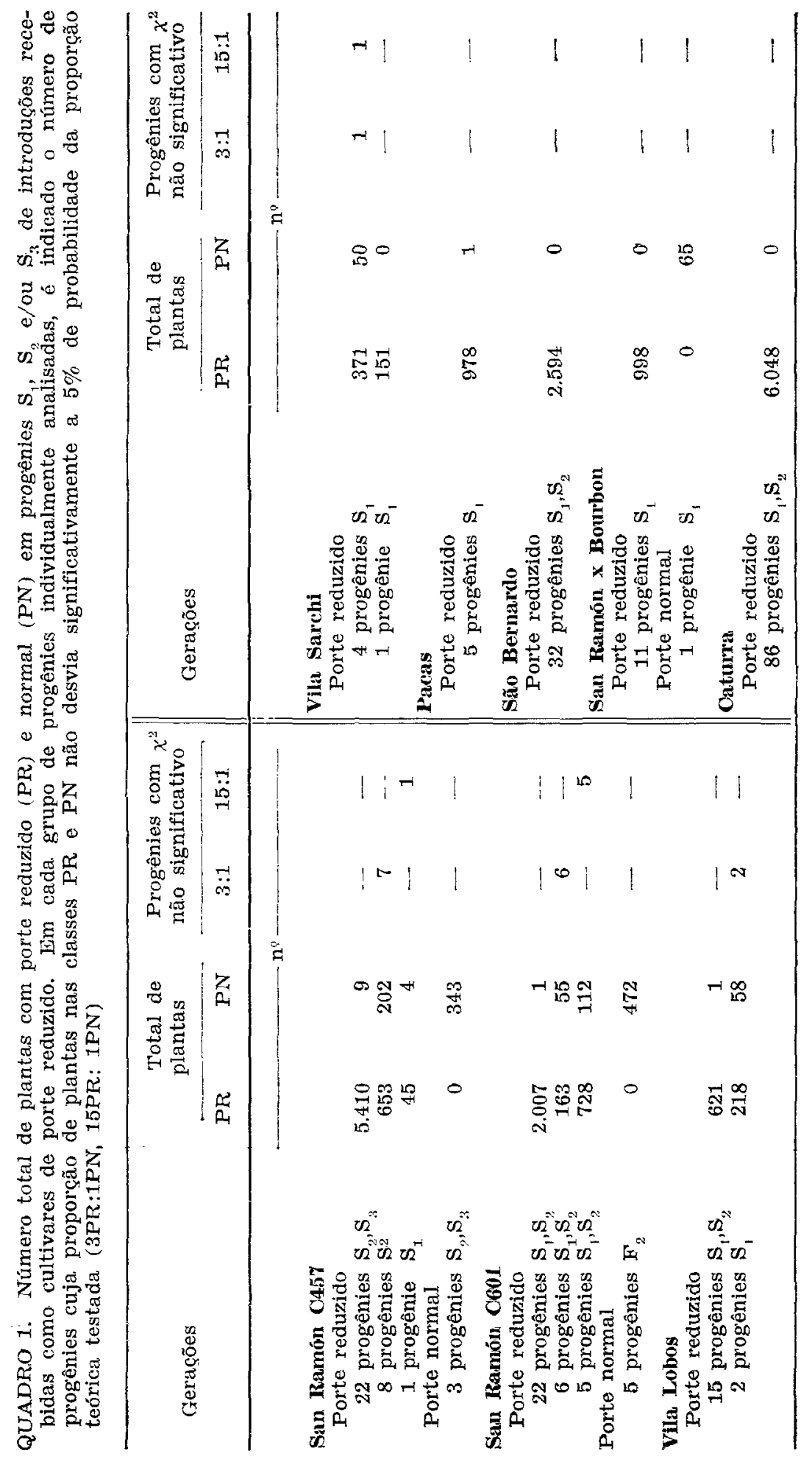




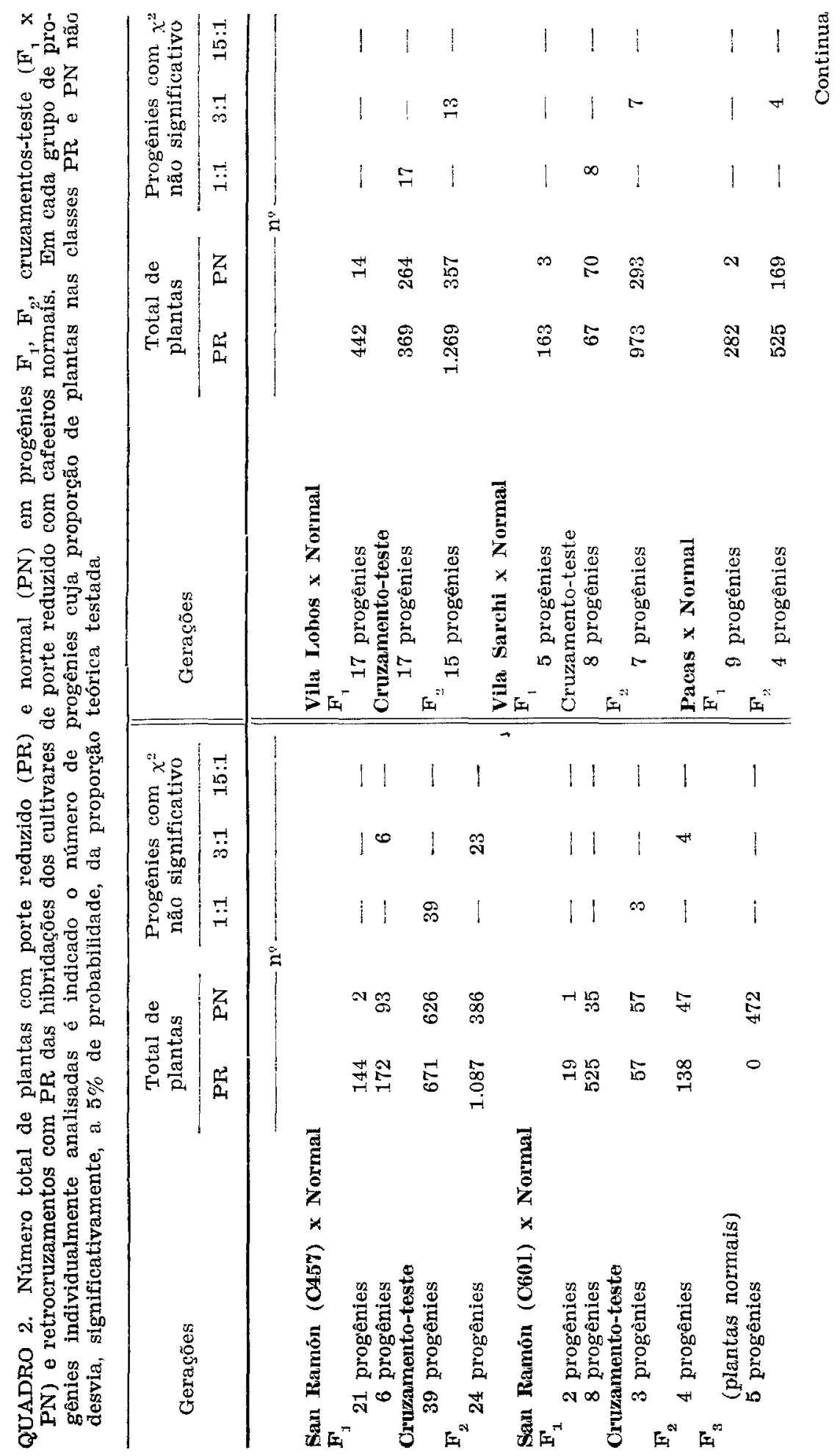




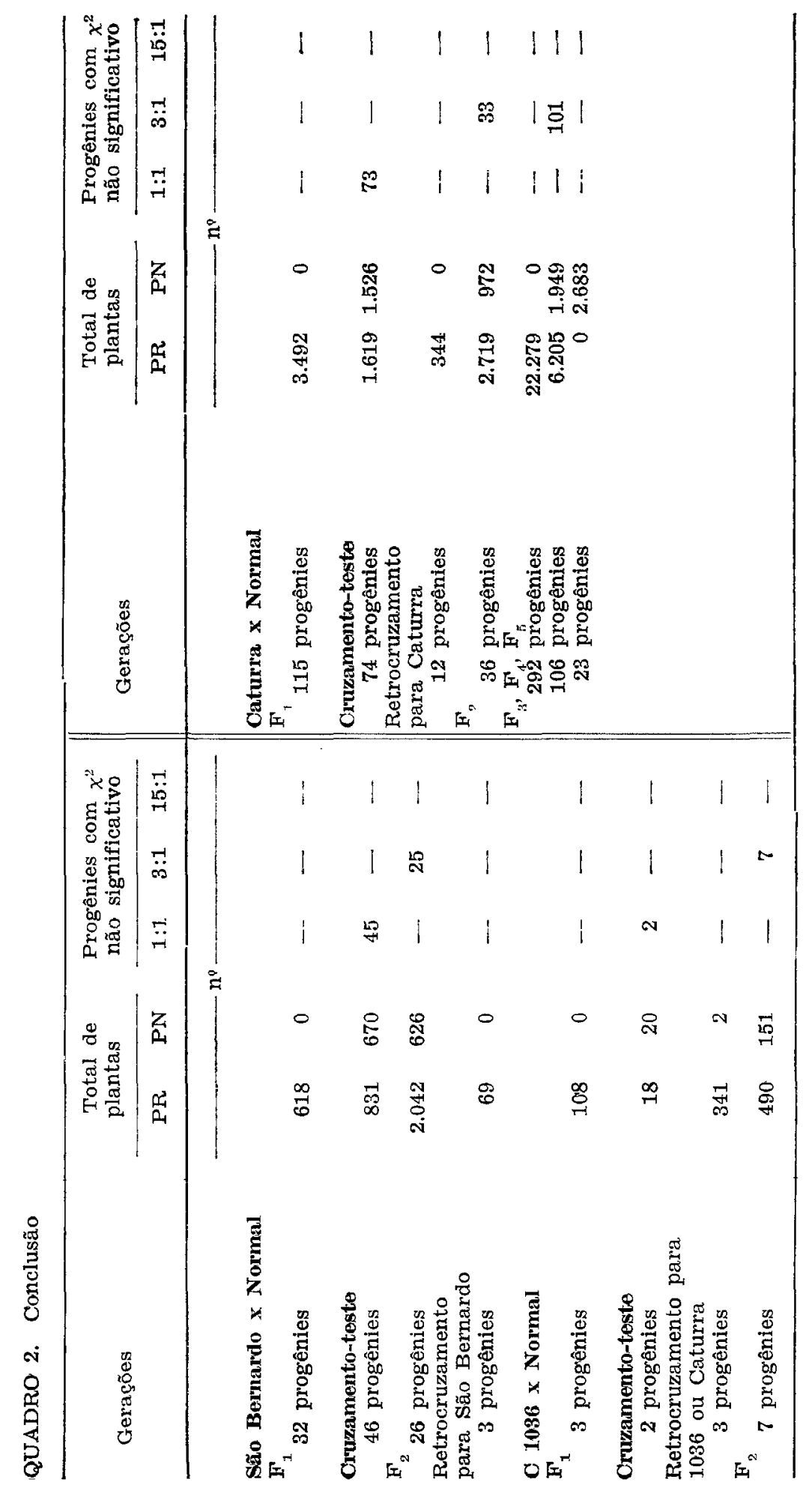




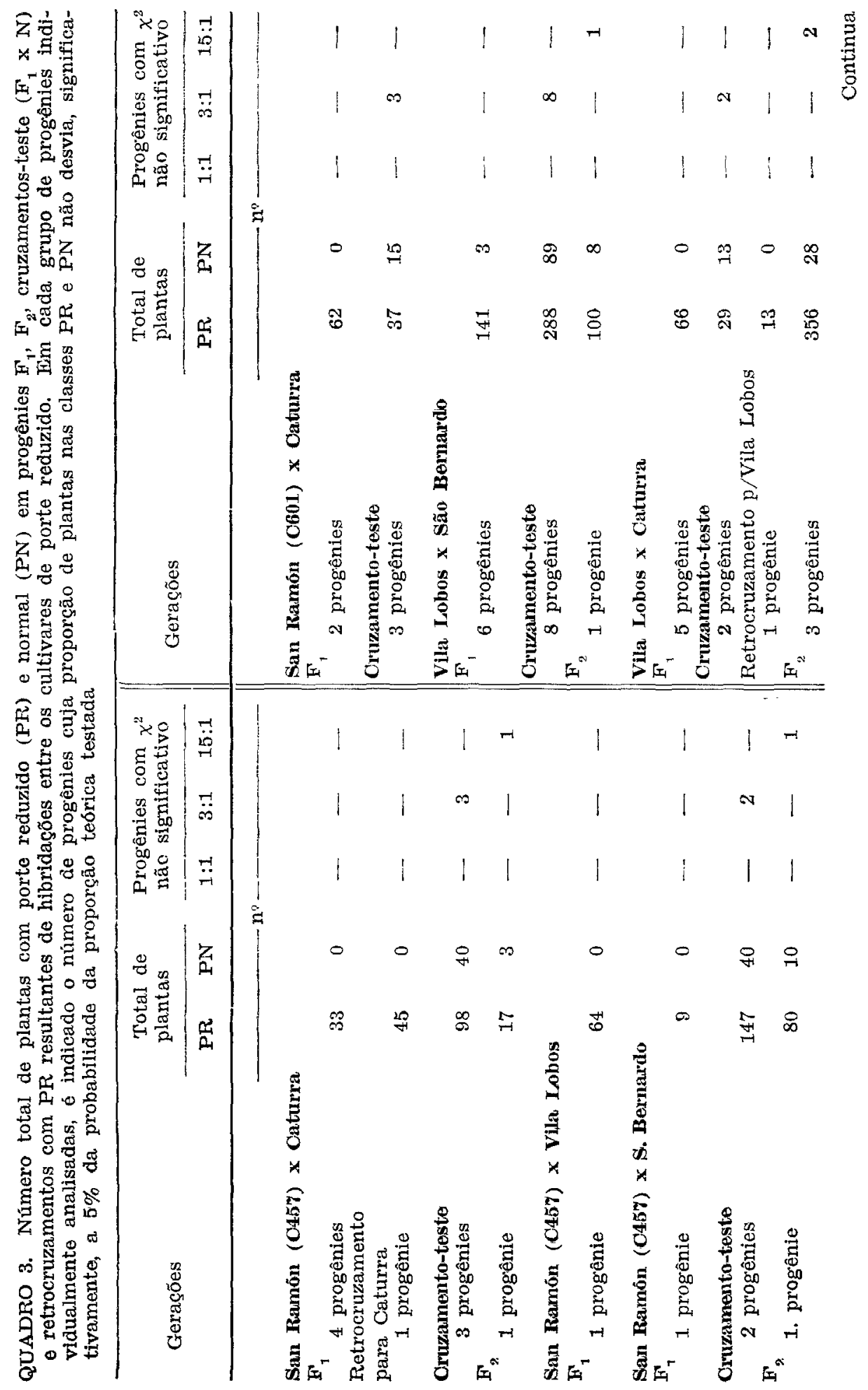




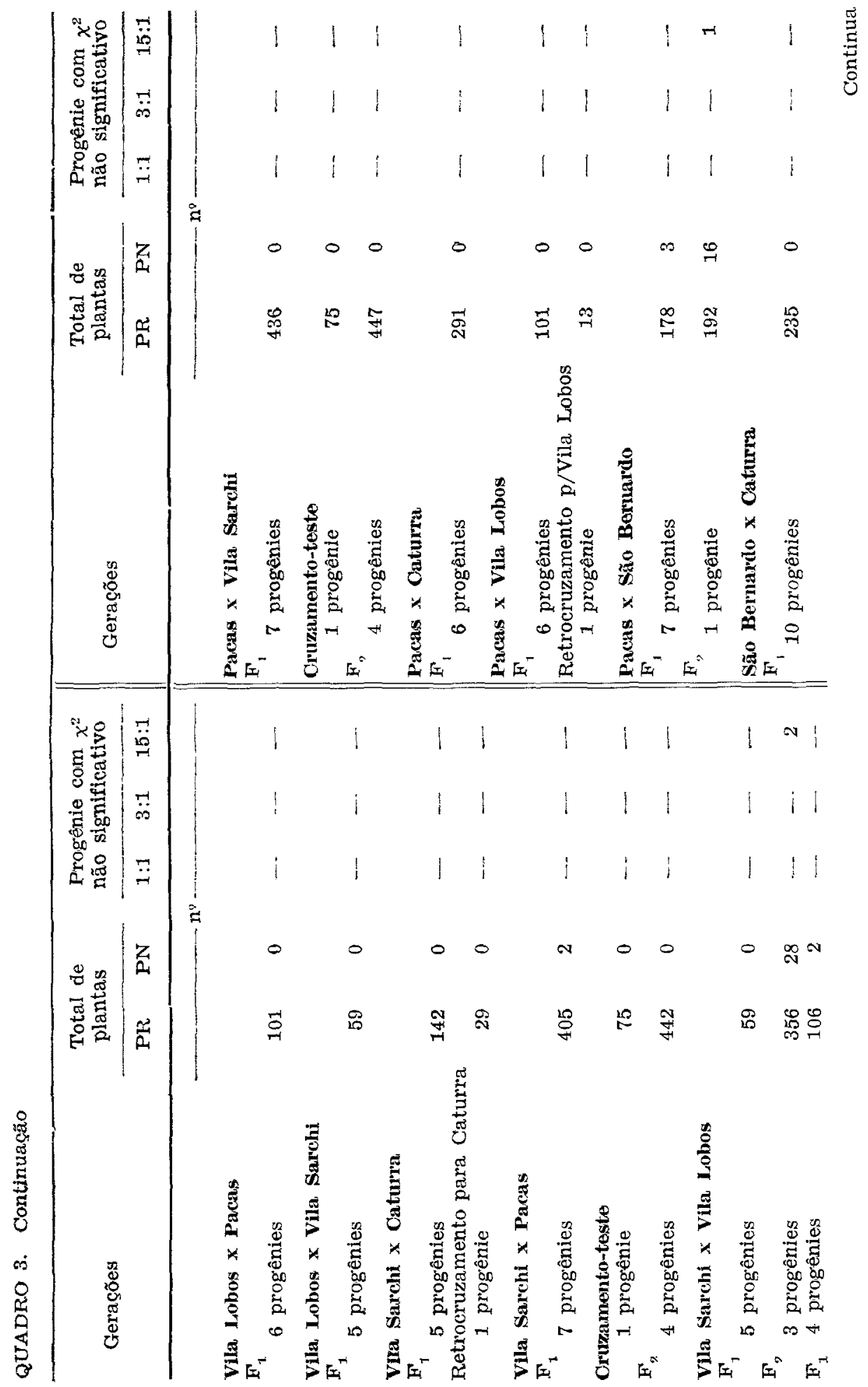




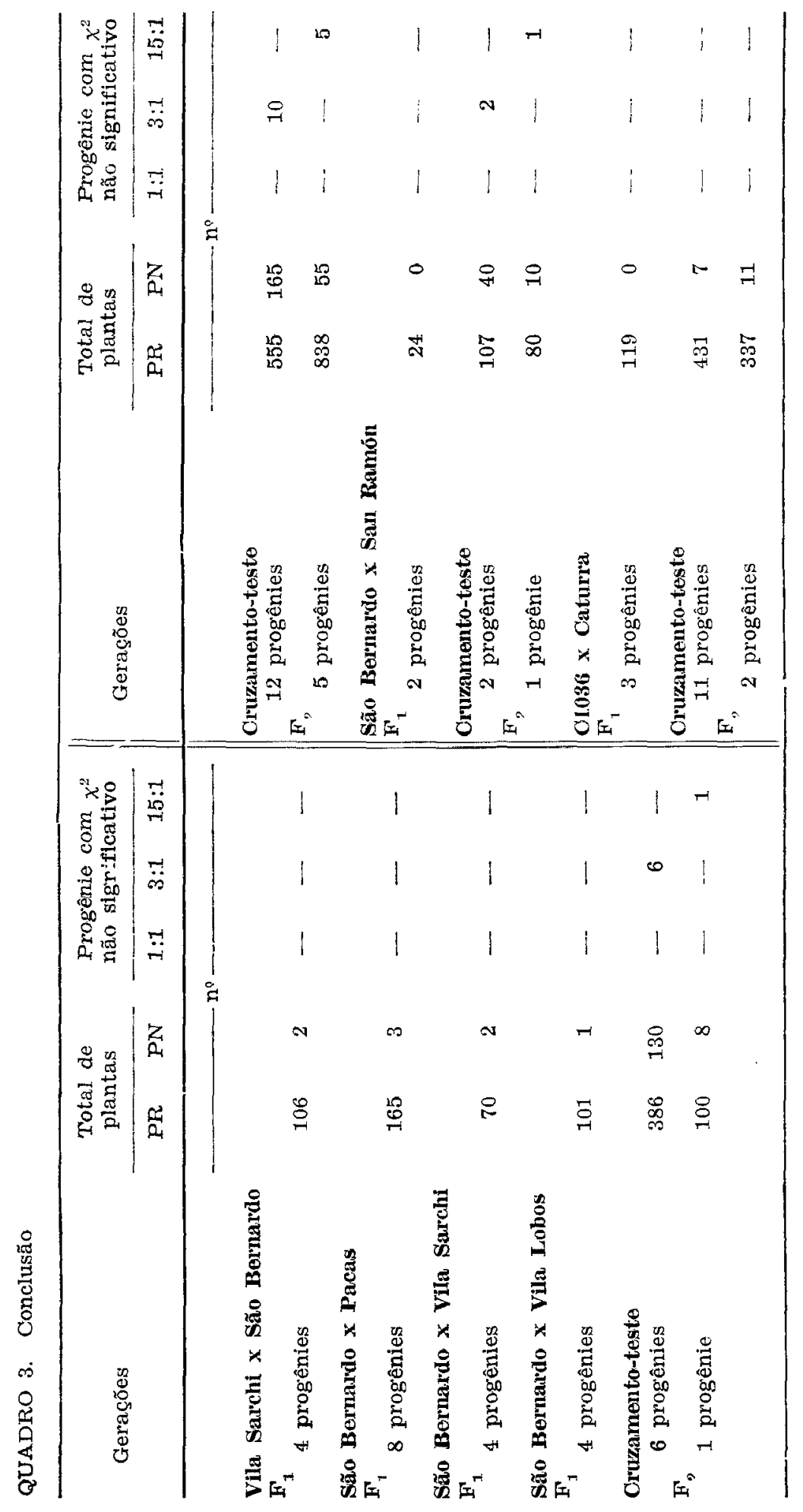


Com referência às tentativas de classificação de populações segre gando para dois fatores independentes, em quatro classes no $\mathbf{F}_{2}(9: 3: 3: 1)$ e no cruzamento-teste em quatro classes $(1: 1: 1: 1)$, cabe ressaltar que foram infrutíferas. Nos casos em que isso foi tentado, verificou-se que o número de plantas nas classes contendo um ou mais fatores dominantes foi praticamente aleatório. Entretanto, as mesmas populações analisadas, agrupando-se essas classes, mostraram uma perfeita segregação mendeliana de 15:1 $\left(\mathrm{F}_{2}\right)$ ou de 3:1 (cruzamento-teste). Esse fato sugere a dificuldade de distinguir as classes genotipicas mencionadas, evidenciando, portanto, a interação entre locos do tipo epistasia duplo dominante. Em outras palavras, as plantas homozigotas ou heterozigotas para um ou dois alelos dominantes condicionando porte reduzido são, pelo critério empregado, indistinguíveis entre si, sendo, porém, distintas daquelas de porte normal.

De acordo com essas considerações, verifica-se que a introdução C 1036 e o Caturra, assim como Pacas e Vila Sarchi, possuem alelos para um mesmo loco. Segregações diíbridas são observadas nas gerações segregantes a partir das seguintes combinações envolvendo os cultivares de porte reduzido Caturra (CA), São Bernardo (SB), San Ramón (SR), Pacas (PA), Vila Sarchi (VS) e Vila Lobos (VL): VL x SB (e cruzamento recíproco), VL $\times$ CA, PA x SB, SB x CA, SB x SR (e cruzamento reciproco), VS $\mathrm{x}$ VL e SR $\mathrm{x}$ CA.

Considerando que o fator da introdução C 1036 é alelo àquele do Caturra e o fator de Pacas é alelo ao de Vila Sarchi, para fins de simplificação na discussão que se segue, pode-se referir simplesmente como os fatores presentes em CA e PA. Verifica-se, então, que as seguintes combinações não foram extensivamente estudadas: CA x PA, PA x SR e SR $\times$ VL.

As relações entre esses cultivares poderiam ser conhecidas somente pela análise dos descendentes dos cruzamentos indicados, como foi realizada com as demais combinações. No entanto, poderiam ser feitas algumas conjecturas sobre a possível relação entre eles, em termos de alternativas condicionais. Um resumo das relaçōes de independência entre eles é apresentado na figura 1.

A título de simplificação, chamemos as combinações alélicas de igual $(\Leftrightarrow)$ e as não alêlicas ou independentes de diferentes $(\neq)$. Da análise da figura 1, conclui-se que $\mathrm{CA} \neq \mathrm{SB}, \mathrm{CA} \neq \mathrm{SR}$ e $\mathrm{SB} \neq \mathrm{SR}$, donde se conclui que pelo menos três locos estão envolvidos (presentes em CA, SB e SR). Conclui-se, também, que nos cultivares analisados, um máximo de cinco locos diferentes poderia ser identificado (presente em CA, SB, VL, PA e SR).

No caso de cinco locos estarem envolvidos, $\mathrm{PA} \neq \mathrm{CA}, \mathrm{SR} \neq \mathrm{VL}$ e $\mathrm{VL} \neq \mathrm{PA}$, cada cultivar possuiria então um fator independente dos demais. 


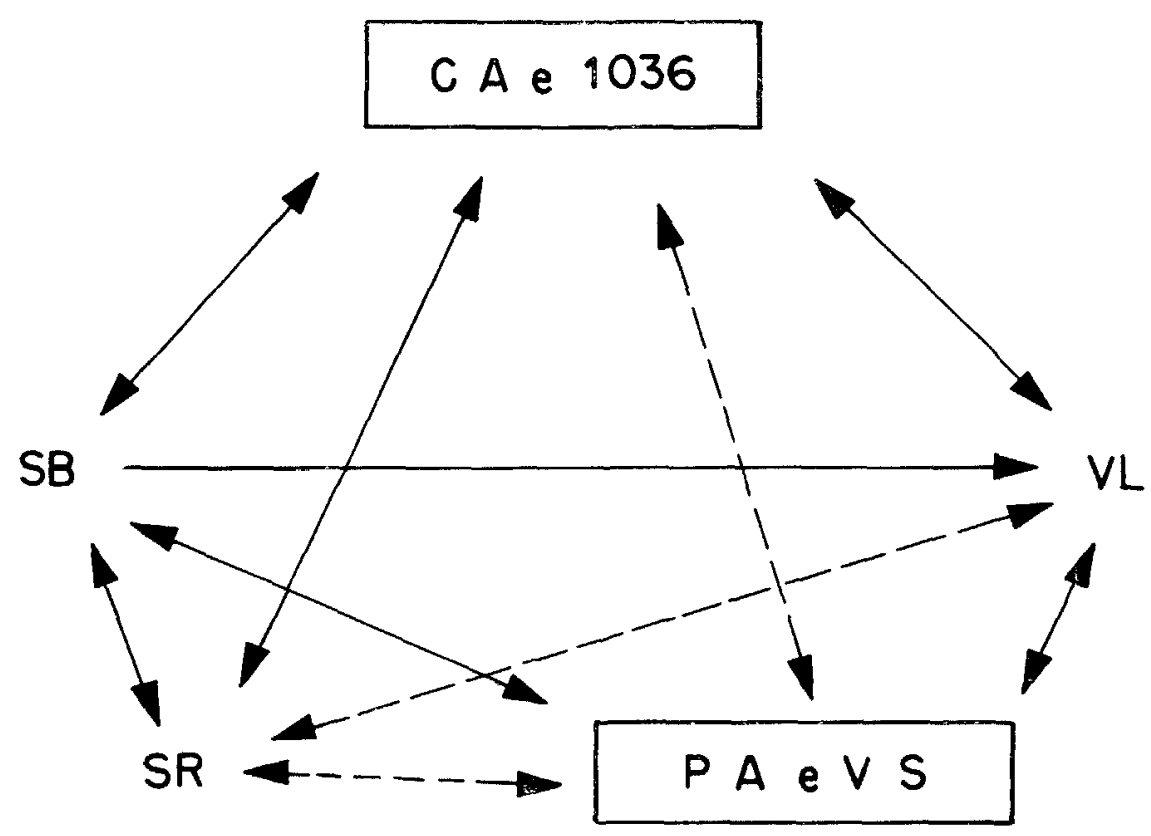

FIGURA 1. Relações genéticas entre os fatores para porte reduzido presentes nos cultivares Caturra (CA), San Ramon (SR), São Bernardo (SB), Pacas (PA), Vila Sarchi (VS), Vila Lobos (VL) e na introdução 1036. Cultivares agrupados nos quadros possuem alelos do mesmo loco. Linhas cheias indicam cultivares possuindo alelos em locos diferentes, segregando independentement $\epsilon$. Linhas interrompidas indicam relações não conhecidas.

Portanto, tanto quanto se pode inferir pela análise genética realizada, um minimo de três (Ct, $\mathbf{S b}$ e $\mathbf{S r}$ ) e um máximo de cinco locos condicionam a característica porte reduzido nos sete materiais estudados. Há ainda que considerar que em algumas plantas do tipo San Ramón, parece ocorrer segregação para fatores duplicados, o que aumentaria para mais um o número de locos envolvidos, caso não fosse alelo a algum dos presentes nos demais cultivares.

A origem de Coffea arabica $(2 n=4 x)$ e a natureza poliplóide de seu genoma têm sido conjecturadas por diversos pesquisadores, sendo um tema ainda bastante debatido (19). No entanto, parece provável que se trate de uma espécie alopoliplóide, em cuja formação estariam envolvidas duas espécies relacionadas. Dessa forma, seria esperado em C. arabica a ocorrência freqüente de fatores duplicados, presentes nos cromossomos homeólogos. Apesar disso, raros são os casos de características controladas por fatores duplicados, embora já tenham sido geneticamente estudados mais de quarenta mutantes $(3,15)$.

A análise dos fatores que controlam o porte reduzido mostra que pelo menos três locos estão envolvidos no controle dessa característica, 
todos com uma ação gênica dominante e interagindo de forma semelhante. É possível que dois deles estejam situados em cromossomos homeólogos. Permaneceria então a interessante especulação sobre a localização do terceiro e possivelmente dos demais locos. Seria de grande interesse que fossem realizados estudos fisiológicos e bioquímicos visando ao conhecimento dos efeitos dos diversos fatores controlando a redução do porte, nos sistemas hormonais, principalmente relativos a auxinas e giberelinas. Se verdadeira a hipótese de que dois dos fatores estariam localizados em cromossomos homeólogos, seus produtos gênicos seriam relacionados e os efeitos fisiológicos de sua ação provavelmente semelhantes.

Tanto quanto se sabe, Ct (presente no cv. Catuai) é insensivel a aplicações exógenas de ácido giberélico (25), enquanto $\mathbf{S b}$ e $\mathbf{S r}$ e aquele das plantas de porte normal respondem positivamente, com acentuada elongação dos internódios $(\boldsymbol{\gamma}, \mathbf{2 4})$. Uma vez que o efeito do alelo $\mathbf{C t}$ não é revertido pela aplicação exógena de giberelina, enquanto $\mathbf{S b}$ e $\mathbf{S r}$ o são, poder-se-ia especular que: a) Ct seria um locos não relacionado com $\mathbf{S b}$ nem com $\mathbf{S r}$ e que $b$ ) $\mathbf{S b}$ e $\mathbf{S r}$ seriam evolutivamente relacionados e, como segregam independentemente, poderiam estar localizados em cromossomos homeólogos.

Hibridações foram realizadas entre os cultivares San Ramón e Caturra com plantas da variedade murta (C. arabica var. murta), a fim de estudar sua origem. Nos cruzamentos, notou-se segregacão para planta tipo murta (tt Na na) apenas para os híbridos com Caturra, enquanto aqueles híbridos com San Ramón deram apenas plantas normais. Isso indica que o San Ramón provavelmente se originou do cultivar Arábica (TT Na Na), enquanto o Caturra é oriundo do Bourbon (tt Na Na) (5).

Os resultados do presente trabalho sugerem que o potencial genético para a redução da altura dos cafeeiros é atingido quando se introduz um par de alelos dominantes em qualquer dos locos envolvidos, visto que não existem acentuados efeitos aditivos em combinações duplo dominantes. Entretanto, a validade dessa conclusão é de certa forma restrita, uma vez que: a) não foram realizados estudos criticos quantificando o efeito de alelos dominantes em dois locos diferentes; b) não foram estudadas combinações genotípicas de alelos dominantes em mais de dois locos e, c) existe ainda a possibilidade da ocorrência de fatores modificadores nos diferentes germoplasmas de $\mathbf{C}$. arabica, ainda não investigados.

Em vista dessas considerações, não poderia ser totalmente excluido o interesse de a introdução de alelos $\mathbf{S b}$ e $\mathbf{S r}$ em cultivares de café de baixa estatura e alta produtividade, como o Catuaí, produzir um germoplasma com características comerciais interessantes. Seria, portanto, desejável estender os estudos sobre o efeito da combinação de diversos alelos para baixa estatura, em plantas adultas, em condiçôes de campo, não somente para explorar a possibilidade de maior redução no porte como, também, diversificar o germöplasma comercial disponível. 


\section{SUMMARY}

\section{NUMBER OF LOCI AND GENE ACTION OF SHORT STATURE FACTORS IN COFFEA ARABICA L.}

A genetic analysis was performed for short stature factors present in the following Coffea arabica cultivars: Caturra (C 476, C 477), São Bernardo (C 1039), Pacas (C 1467), Vila Sarchi (C 1468), San Ramon x Bourbon (C 1036), Vila Lobos (C 1089) and San Ramón (C 457 and C 601). Crosses were made between them and with $\mathbf{C}$. arabica cv Arabica taken as the standard genotype. The results reported here are the outcome of a study of 91,358 plants comprising investigations on generations $\mathbf{S}_{1}, \mathbf{S}_{2}, \mathrm{~S}_{3}, \mathbf{F}_{1}, \mathbf{F}_{2}, \mathrm{BC}$ and test crosses. Short stature in each cultivar is controlled by a single gene, dominant to the allele for normal plant height of cv. Arabica. Three loci were identified - São Bernardo (Sb), San Ramón (Sr) and Caturra (Ct) - assorted independently from dihybrid combinations. Other loci may also be involved. Pacas and Vila Sarchi factors are alleles of the same locus while accession C 1036 carries an allele of Ct. The analysis is not yet conclusive to ascertain whether the factors present in Vila Lobos and San Ramon (Sr) are alleles, despite the fact that both segregate independently from Ct and Sb. In addition, the factor present in Vila Lobos is independent from the factor found in Pacas or Vila Sarchi. The analysis of $F_{1}, F_{2}, B C$ and test crosses for dihybrid combinations revealed that they interact in typical duplicate dominant epistasis, the presence of one dominant allele in one locus masking the effect of the other. Seedlings homozygous or heterozygous for a dominant allele, at one or two loci, have the same short stature phenotype.

\section{REFERÊNCIAS BIBLIOGRÄATCAS}

1. ANTUNES FILHO, H. \& CARvalHo, A. Genetics of Coffea. XVT: The variety typica as a standard for genetical studies of Coffea arabica. Journal of Heredity, 48:110-117, 1957.

2. BIERBIGER, A. The creation of semi-dwarf barley varieties. Euphytica, 17:177-184, 1968. (Supplement, 1)

3. CARVAlHo, A. Advances in coffee production technology. Recent advances in our knowledge of coffee trees. 2, Genetics. Coffee and Tea Industries and the Flavor Field, 81:30-36, 1958.

4. \& KRUG, C.A. Agentes de polinização da flor do cafeeiro (Coffea arabica L.). Bragantia, Campinas, 9:11-24, 1949.

5. - ; MENDES, J.E.T.; ANTUNES FTlHO, H.; MORAES, H.; ALOISI SOBRINHO, J.; MORAES, M.V.; ROCHA, T.R. Melhoramento do cafeeiro. IV. Café Mundo Novo. Bragantia, Campinas, 12:97-129, 1952.

6. __ \& MONACO, L.C. Natural cross-pollination in Coffea arabica. In: INTERNATIONAL HORTICULTURAL CONGRESS, 14. Brussels, Belgium, 1962. p.447. (Separata)

7. - _ \& Observaçōes preliminares sobre o efeito da giberelina em mutantes de café. O Agronômico, Campinas, 10(3/4):1-4, 1958.

8. - Transferência do fator Caturra para o cultivar Mundo Novo de Coffea arabica. Bragantia, Campinas, 31:379-399, 1972.

9. CHOUssy, F. Café San Ramón. In: El café San Ramón, El Salvador, Asociación Cafetalera de El Salvador, 1935. v.1, p.68-72. 
10. GONZALEZ, J.A. Variedades del café de importancia en El Salvador. In: MANUAL tecnico del cultivo del café en El Salvador. Santa Tecla, EI Salvador, ASIC Instituto Salvadoreño de Investigaciones del Café, 1976. p.19-21.

11. GONZALEZ, J.P. \& CAMPOS, E.C. El café en Costa Rica. Costa Rica, Oficina del Café, 1981. 18p. (Informe geral)

12. HANSCHE, P.E.; HESSE, C.O.; BEUTEL, J.; BERES, W.; DOYLE, J. The commercial potential of dwarf fruit trees. California Agriculture, $33(9)$ : 4-6, 1979.

13. INFORME ANUAL DE LABORES. Programa Cooperativo Oficina del Café, 1980. San José, Costa Rica, Ministerio de Agricultura y Ganaderia, 1981. p.29-46.

14. KRUG, C.A. Controle da polinização nas flores do cafeeiro. Campinas, Instituto Agronômico, 1937. 12p. (Boletim técnico, 15)

15. \& CARVAlHo, A. The Genetics of Coffea. Advances in Genetics, $4: 127-158,1951$.

16. - - MENDES, A.J.T.; CARVALHO, A. Taxonomia de Coffea arabica L. II. Coffea arabica L. var. caturra e sua forma xantocarpa. Bragantia, Campinas, 9:157-163, 1949.

17. - ; MENDES, J.E.T.; CARVALHO, A. Taxonomia de Coffea arabica. Descrição das variedades e formas encontradas no Estado de São Paulo. Campinas, Instituto Agronômico, 1938. 57p. (Boletim Técnico, 62)

18. LITTLE, T.M. \& HILLS, F.J. Agricultural Experimentation. New York, Wiley, 1968. 350p.

19. MEDINA FILHO, H.P.; CARVALHO, A.; SONDAHL, M.R.; FAZUOLI, L.C.; COSTA, W.M. Coffee breeding and related evolutionary aspects. In: JANICK, J., ed. Plant Breeding Reviews. Connecticut, Avi, 1983. (in press)

20. PAQUET, J. Effects of a selection for semi-dwarfness on the other characters of bread wheat (autumn sown). Euphytica, 17:131-142, 1968. (Supplement, 1)

21. PELTON, J.S. Genetic and morphogenetic studies of Angiosperm single-genedwarf. Botanical Review, (July-Sept.):479-512, 1964.

22. PLUCKNETT, D.L. \& SMITH, N.J.H. Agricultural research and third world food production. Science, 217:215-220, 1982.

23. RUTGER, J.N. \& PETERSON, M.L. Improved short stature rice. California Agriculture, 30(6):4-6, 1976.

24. SONDAHL, M.R.; MONACO, L.C.; FAZUOLT, L.C.; CARVALHO, A. Influência do modo de aplicação e de doses de ácido giberélico em plantas de café. Ciência e Cułtura, São Pauło, 23:256, 1971. (Suplemento)

25 .

; MEDINA FILHO, H.P.; LIMA, M.A. Resposta de germoplasma de Coffea arabica a benzil-adenina e giberelina. Turrialba, 27 (3) :215-219, 1977.

26. STEEL, R.G.D. \& TORRIE, J.H. Principles and Procedures of Statistics. New York, McGraw-Hill, 1960. 481p.

27. URIBE-HENAO, A. \& SALAZAR-ARIAS, N. Distancias de siembra y dosis de fertilizante en la producción de café. Cenicafé, Colombia, 32(3):88$105,1981$. 